\title{
Recurrent Giant Intrahepatic Biliary Cystadenoma: Case Report and Review of Literature
}

\begin{abstract}
Biliary cystadenoma is a very rare cystic neoplasm of the liver that usually occurs almost exclusively in middle-aged women. These are slowly progressive tumours and cannot be safely differentiated from cystadenocarcinomas on preoperative imaging and hence should always be considered for resection. Historically these cystic tumors have been treated by a variety of techniques including aspiration, fenestration, internal drainage, partial resection resulting in high rates of recurrence. In addition biliary cystadenoma is a premalignant lesion and only surgical excision can differentiate it from its malignant counterpart, biliary cystadenocarcinoma.
\end{abstract}

Keywords: Cystic neoplasm of liver, enucleation, recurrent giant biliary cystadenoma

\section{Introduction}

Biliary cystadenomas (BCAs) are rare cystic neoplasms of the liver. They form $<5 \%$ of nonparasitic cysts of the liver ${ }^{[1]}$ and occur almost exclusively in middle-aged women. The size varies from 1.5 to $35 \mathrm{~cm}^{[2,3]}$ They need to be differentiated from other cystic lesions such as simple cysts, hydatid cysts, abscesses, hematomas, and polycystic liver disease.

BCAs were first described in $1943,{ }^{[4]}$ and only a few hundred cases have been reported in the literature till date, most being case reports. They are usually benign lesions with a malignant potential. ${ }^{[3]}$ They develop from either an aberrant bile duct or directly from a primitive hepatobiliary stem cell. ${ }^{[1,5,6]}$ Majority are intrahepatic $(85 \%),{ }^{[5,7-9]}$ few are extra hepatic ${ }^{[5,10]}$ and very rarely arise from the gallbladder. ${ }^{[9,11]}$

It is extremely difficult to differentiate a benign from a malignant BCA preoperatively based on imaging, and hence, these lesions should always be resected. Previously, deroofing, marsupialization, or partial resection of such suspicious cysts has led to a high rate of recurrence $(>90 \%)$. ${ }^{[12]}$ Hence, resection or enucleation of the cyst is the treatment of choice. We report a case of recurrent giant intrahepatic BCA in a middle-aged woman which is the largest

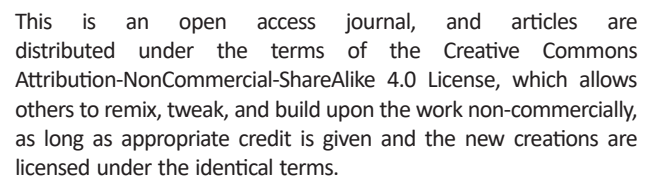

For reprints contact: WKHLRPMedknow_reprints@wolterskluwer.com
$\mathrm{BCA}$ reported in the literature till date to the best of our knowledge.

\section{Case Report}

A 30-year-old female patient presented with complaints of a large mass in the abdomen associated with pain. She was diagnosed to have a liver cyst for the past 3 years and underwent cystojejunostomy elsewhere. She had a recurrence of symptoms of 6 months postsurgery, and multiple aspirations were done from the cyst before being referred to our department. General physical examination was within normal limits, and abdominal examination revealed a large mass occupying the entire abdomen. Her routine blood investigations including liver function tests were within normal limits. Tumor markers, alpha-fetoprotein, and CA 19-9 were normal. Triphasic contrastenhanced computerized tomography (CECT) abdomen revealed a large multiloculated cyst of size $35 \mathrm{~cm} \times 26$ $\mathrm{cm}$ arising from segments $4 \mathrm{~B}, 5$, and 6 of liver extending up to pelvis with enhancing septa and mural nodules suggestive of BCA [Figure 1]. Intraoperatively, a large $39 \mathrm{~cm} \times$ $28 \mathrm{~cm}$ multiloculated cyst was arising from segments 4B, 5, and 6 of liver. Complete enucleation of the cyst was done. Resection was not attempted given proximity to hepatic hilum and indentation of hilar structures [Figure 2]. Final histopathology confi rmed the diagnosis of BCA

\footnotetext{
How to cite this article: Sharma D, Gondu GR, Thamma VM, Gunturi SR, Kishore KN, Reddy JM, et al. Recurrent giant intrahepatic biliary cystadenoma: Case report and review of literature. Indian J Med Paediatr Oncol 2020;41:69-71.
}

\author{
Digvijoy Sharma, \\ Gangadhar Rao \\ Gondu, \\ Venu Madhav \\ Thamma, \\ Surya Ramachandra \\ Varma Gunturi, \\ Kunduru Nava \\ Kishore, \\ Jagan Mohan \\ Reddy, \\ Nagari Bheerappa
}

Department of Surgical Gastroenterology, Nizams Institute of Medical Sciences, Hyderabad, Telangana, India

Submitted: $26-$ Feb-2018 Accepted in Revised Form: 18-Apr-2018

Published: 24-Apr-2020

Address for correspondence: Dr. Nagari Bheerappa, Department of Surgical Gastroenterology, Nizams Institute of Medical Sciences, Hyderabad, Telangana, India. E-mail: nbheerappa62@gmail. com

Access this article online

Website: www.ijmpo.org

DOI: 10.4103/ijmpo.ijmpo_49_18 Quick Response Code:

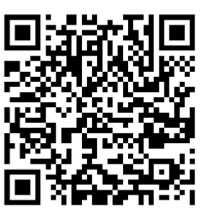




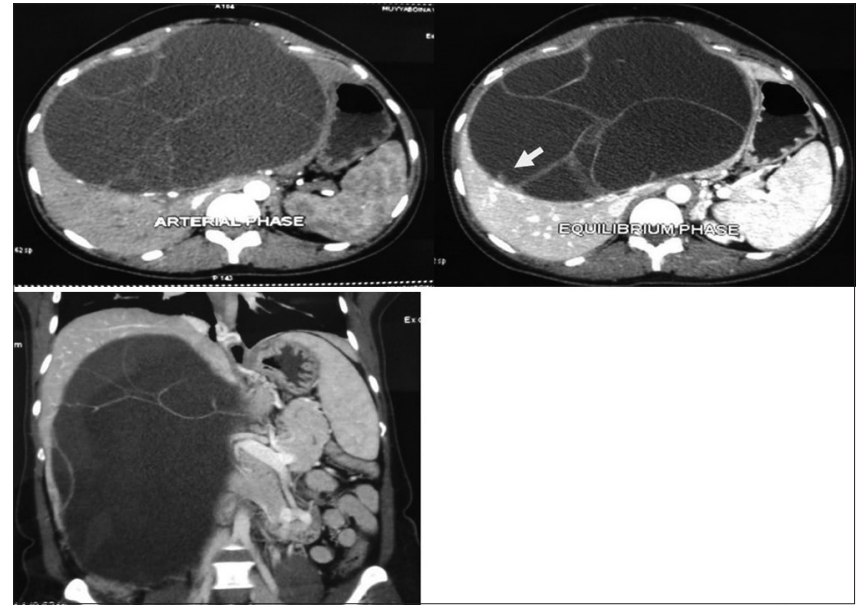

Figure 1: Triphasic computed tomography showing biliary cystadenoma with mutiloculations, septa, and mural nodule (arrow) and extension up to the pelvis

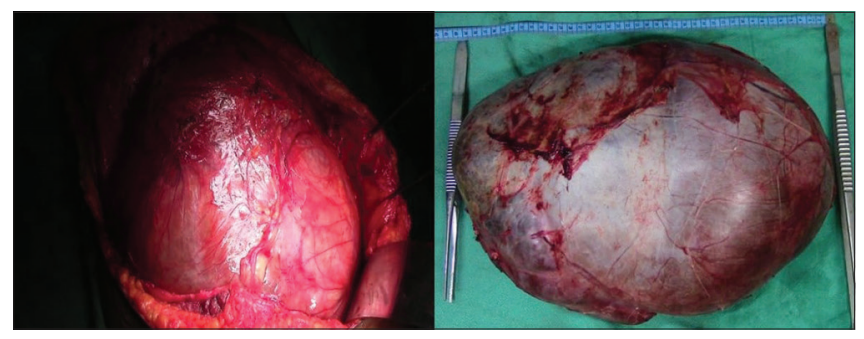

Figure 2: Intraoperative photograph of the cyst and enucleation specimen



Figure 3: ( $a$ and $b$ ) Sections showing cuboidal lining of cyst with subjacent cellular compact ovarian-like mesenchymal stroma, beneath which there is a fibrous layer ( $H$ and $E)$. Immunohistochemistry showing nuclear positivity for (c) estrogen receptor and (d) progesterone receptor and cytoplasmic positivity for (e) smooth muscle actin in the ovarian-like stroma. On immunohistochemistry, (f) carcinoembryonic antigen is seen staining the luminal border of lining cells
[Figure 3]. The patient is symptom free and recurrence free at 6 months of follow-up.

\section{Discussion}

BCAs constitute $<5 \%$ of cystic space-occupying lesions of the liver. It occurs generally in middle-aged women presenting with abdominal pain and/or discomfort, distension, and sometimes a palpable mass. ${ }^{[1,5,11]}$ The almost exclusive occurrence in females and associated increase in size during pregnancy and following oral contraceptives suggest hormonal dependency. ${ }^{[1,2,12]}$

BCAs are usually multiloculated, septated cystic tumors, and are of two types as follows: with ${ }^{[1,6]}$ ovarian-like and without ovarian-like stroma. Wheeler and Edmondson initially defined BCAs in 1958 as multilocular lesions with ovarian-like stroma, but subsequently, BCAs without ovarian stroma were reported. Cystadenomas with ovarian stroma are considered premalignant with a good prognosis, while those without ovarian stroma have a higher risk of transformation to malignancy and have a poorer prognosis. ${ }^{[6,7]}$ The majority of BCAs do not communicate with the bile ducts, but rarely it may be present. ${ }^{[2]}$ Differential diagnosis of cystadenomas includes simple liver cysts, parasitic cysts (particularly hydatid cyst), liver abscess, polycystic liver disease, biliary cystadenocarcinoma, and cystic metastases. ${ }^{[7,8,11]}$ Diagnosis of BCAs is often possible on imaging in the form of ultrasonography, CECT, and MRI abdomen. On all these imaging modalities, the presence of multiloculated cyst, septations, internal echoes, and mural nodules with papillary projections $^{[7,13]}$ is typical. CECT, in addition, delineates the anatomic relation to the surrounding structures, particularly major vessels. ${ }^{[11,13]}$ In spite of all the advanced imaging modalities and the aforementioned radiological features, the preoperative radiological diagnostic accuracy may be as low as $30 \%$, leading to misdiagnosis, and therefore, a high index of suspicion is needed. ${ }^{[14]}$ A preoperative core needle biopsy or fine-needle aspiration cytology to detect malignancy is not recommended, especially in operable lesions due to nonaccuracy and the risk of needle seeding and dissemination. ${ }^{[15,16]}$ Elevated carcinoembryonic antigen and CA 19-9 in the serum or the cystic fluid may aid in diagnosis and follow-up of patients. ${ }^{[17]}$ A normal level, however, does not exclude a BCA; hence, these procedures are not commonly done.

The important issues while making a diagnosis of BCA are the incomplete excision of the cyst, misdiagnosed as a simple cyst or a hydatid cyst, resulting in recurrence, and the difficulty in differentiating BCAs from biliary cystadenocarcinomas, ${ }^{[1,7,10]}$ preoperatively or intraoperatively. Hence, the recommendation is to completely resect any suspected BCA. ${ }^{[1,10]}$ Since it closely resembles other cystic Space occupying lesion (SOLs) of liver, any suspicion intraoperatively warrants a resection. Intraoperative frozen section of the cyst is 
a useful aid in such situations as it can differentiate a BCA from other cystic lesions of liver but not biliary cystadenocarcinoma. Historically, BCAs have been treated with various procedures such as marsupialization, internal Roux-en-Y drainage, aspiration, or partial resection. However, all these procedures have been associated with high rates of recurrence..$^{[5,7,12,18,19]}$ Hence, complete resection is the recommended treatment with negligible recurrence. ${ }^{[6]}$ Pinson et al. ${ }^{[20]}$ have reported cyst enucleation without late recurrence and mortality. This procedure is a valid alternative where resection is difficult or is likely to be associated with higher morbidity. ${ }^{[10]}$

In conclusion, the diagnosis of BCA should be considered in any multilocular cystic lesion of the liver, especially recurrent cysts, particularly in a middle-aged woman. The recommended treatment of choice for any suspected BCA is resection as it is extremely difficult to differentiate it from cystadenocarcinoma preoperatively. Enucleation is another feasible option and is indicated where resection is difficult due to the location of the tumor and proximity to hepatic hilum and major vessels.

\section{Financial support and sponsorship}

Nil.

\section{Conflicts of interest}

There are no conflicts of interest.

\section{References}

1. Wheeler DA, Edmondson HA. Cystadenoma with mesenchymal stroma (CMS) in the liver and bile ducts. A clinicopathologic study of 17 cases, 4 with malignant change. Cancer 1985;56:1434-45.

2. Del Poggio P, Buonocore M. Cystic tumors of the liver: A practical approach. World J Gastroenterol 2008;14:3616-20.

3. Tsiftsis D, Christodoulakis M, de Bree E, Sanidas E. Primary intrahepatic biliary cystadenomatous tumors. J Surg Oncol 1997;64:341-6.

4. Short WF, Nedwich A, Levy HA, Howard JM. Biliary cystadenoma. Report of a case and review of the literature. Arch Surg 1971;102:78-80.

5. Lewis WD, Jenkins RL, Rossi RL, Munson L, ReMine SG, Cady B, et al. Surgical treatment of biliary cystadenoma. A report of 15 cases. Arch Surg 1988;123:563-8.
6. Vogt DP, Henderson JM, Chmielewski E. Cystadenoma and cystadenocarcinoma of the liver: A single center experience. J Am Coll Surg 2005;200:727-33.

7. Manouras A, Markogiannakis H, Lagoudianakis E, Katergiannakis V. Biliary cystadenoma with mesenchymal stroma: Report of a case and review of the literature. World $\mathrm{J}$ Gastroenterol 2006;12:6062-9.

8. Palacios E, Shannon M, Solomon C, Guzman M. Biliary cystadenoma: Ultrasound, CT, and MRI. Gastrointest Radiol 1990;15:313-6.

9. Marcial MA, Hauser SC, Cibas ES, Braver J. Intrahepatic biliary cystadenoma. Clinical, radiological, and pathological findings. Dig Dis Sci 1986;31:884-8.

10. Thomas KT, Welch D, Trueblood A, Sulur P, Wise P, Gorden DL, et al. Effective treatment of biliary cystadenoma. Ann Surg 2005;241:769-73.

11. Florman SS, Slakey DP. Giant biliary cystadenoma: Case report and literature review. Am Surg 2001;67:727-32.

12. Emre A, Serin KR, Ozden I, Tekant Y, Bilge O, Alper A, et al. Intrahepatic biliary cystic neoplasms: Surgical results of 9 patients and literature review. World J Gastroenterol 2011;17:361-5.

13. Forrest ME, Cho KJ, Shields JJ, Wicks JD, Silver TM, McCormick TL, et al. Biliary cystadenomas: Sonographic-angiographic-pathologic correlations. AJR Am J Roentgenol 1980;135:723-7.

14. Choi BI, Lim JH, Han MC, Lee DH, Kim SH, Kim YI, et al. Biliary cystadenoma and cystadenocarcinoma: CT and sonographic findings. Radiology 1989;171:57-61.

15. Hai S, Hirohashi K, Uenishi T, Yamamoto T, Shuto T, Tanaka H, et al. Surgical management of cystic hepatic neoplasms. J Gastroenterol 2003;38:759-64.

16. Iemoto Y, Kondo Y, Fukamachi S. Biliary cystadenocarcinoma with peritoneal carcinomatosis. Cancer 1981;48:1664-7.

17. Koffron A, Rao S, Ferrario M, Abecassis M. Intrahepatic biliary cystadenoma: Role of cyst fluid analysis and surgical management in the laparoscopic era. Surgery 2004; 136:926-36.

18. Teoh AY, Ng SS, Lee KF, Lai PB. Biliary cystadenoma and other complicated cystic lesions of the liver: Diagnostic and therapeutic challenges. World J Surg 2006;30:1560-6.

19. Fiamingo $P$, Veroux $M$, Cillo $U$, Basso $S$, Buffone $A$, D'Amico DF, et al. Incidental cystadenoma after laparoscopic treatment of hepatic cysts: Which strategy? Surg Laparosc Endosc Percutan Tech 2004;14:282-4.

20. Pinson CW, Munson JL, Rossi RL, Braasch JW. Enucleation of intrahepatic biliary cystadenomas. Surg Gynecol Obstet 1989;168:534-7. 